\title{
The Research Ken of Public Culture Governance: Connotation, Function and Focus
}

\author{
Yufan Yan ${ }^{1,}$, Yuhui Liang ${ }^{2}$ \\ ${ }^{1}$ School of Marxism, Hohai University, Nanjing, China \\ ${ }^{2}$ School of Public Administration, Hohai University, Nanjing, China
}

Email address:

yufanyan2013@163.com (Yufan Yan)

*Corresponding author

\section{To cite this article:}

Yufan Yan, Yuhui Liang. The Research Ken of Public Culture Governance: Connotation, Function and Focus. Humanities and Social Sciences. Vol. 5, No. 4, 2017, pp. 150-154. doi: 10.11648/j.hss.20170504.14

Received: July 2, 2017; Accepted: August 4, 2017; Published: August 14, 2017

\begin{abstract}
Public culture governance is an important part of the national governance system. It is an important means to lead ideology, regulate cultural production and guide people's life. It plays a vital role in political governance, residents' life and cultural industry. The research in this field should focus on the institutional practice of the government, the cultural life of the residents and the daily operation of the cultural service organizations to clarify the interaction mechanism of the multi-participant subject in the field of public culture governance and provide guidance for the practice of public culture service.
\end{abstract}

Keywords: Cultural Governance, Ideology, Life of Public Culture, Cultural Industry, Multi-Interactive

\section{Introduction}

In the transitional period, China has become increasingly challenged in the dramatic social changes, when the social stratification has been intensified, the class interests have become increasingly cured, the hierarchical structure has become more stereotyped, the political system reform and the state governance mechanism are facing great challenges [1]. In the process of promoting public services, the government has had a certain deviation [2], and the community service has not become a "catalyst" to promote the effective community participation of residents [3], the cultural organizations can not regulate the conflicts between residents caused by the scramble for public space [4]. Besides the cultural organizations can not adjust the conflict caused by the competition of residents and public space. Thus, the government does not have an authoritative power which has a long time to maintain a clear command, and have let others have the awareness to obey, but to share the diffuse power that kind of unconscious scattered throughout the population with other organizations [5]. Social governance emerges as the times require in the complex game between civil power and government. In a long period of history, confined to positivism and structural functionalism of the theoretical research paradigm, sociological theoretical care more focused on the social order and system functions aspect which contained the regular social rules and specific things of social facts. This tendency of research often leads researchers to ignore the basic constructive role that cultural life plays for social facts themselves. In fact, "the ancient hierarchical order and social norms in the restrictions on people's behavior at the same time, gave the world and social life its behavior and meaning, order and norms" [6]. Public culture as an "ideology that is driven by more real social forces" [7] can become an effective leading tool for national governance, meaning that as a public culture in the sense of governance tool, it always contains multiple genes of political attributes, economic attributes and life attributes. Public Culture governance is a comprehensive system of governance in multiple dimensions.

The purpose of this study is that it can help the studiers to get the principle of public cultural service system construction. This research with the method of qualitative study has the significance on benefitting the institutional practice of the government, the cultural life of the residents and the daily operation of the cultural service organizations to clarify the interaction mechanism of the multi-participant subject in the field of public culture governance and provide guidance for the practice of public culture service, and giving new ideas to public cultural service system construction. 


\section{The Meaning of Public Culture}

Hannah Arendt believed there was a purely field of public culture and it was a highly visible field where citizens can show themselves through speech and action, which shows an unnatural, man-made and ideal citizen community based on value consensus [8]. In other words, Public culture can regulate and control the relationship between individuals and society through the infiltration and imperceptible influence of personal values, and rely on this set of regulatory mechanisms to regulate the social relationship between individuals and individuals, individuals and groups, and then integrate the individual goals of the members of society with the overall social goals. At the same time, public culture can also lead the mass cultural life by guiding the mass psychology. The common core values develop by public culture will be imperceptible influence people's mental cognition, so that they put their cultural life in the rule of group consciousness, public ideas and common cultural values.

Based on the above cognition, public culture has its publicity, and it includes public philosophy, public norms, public image and public spirit, etc. It provides public cultural products to citizens through public culture service facilities and public cultural activities. Public culture is also a unity of content and form, with the features of mass, shared, cohesion, inclusiveness and times etc.

In the current era of multi-cultural coexistence, when the language environment and cultural development are constantly changing from bottom to top, it respects the cultural needs, tastes and creativity of the members of society, and does not drown out the cultural individuality of every member of society. Therefore, the leading role of this new public culture in the cultural life of the masses will neither make it an elite intellectual culture nor a mass culture in the general sense. The mass cultural life under this new public culture's guidance will always be a self- sustaining soul and development power with a common cultural value system. However, it will provide the members of the society with sufficient individual freedom, so that members of the society can further enhance group identity and social belonging in maintaining their own cultural life.

\section{Three Dimensions of the Connotation of Public Culture Governance}

In the vast achievements of cultural studies, the cognitive dimension of cultural connotations is changing with the changing process of the modernization of democratic countries, which leads to a multiple understanding of the governance of public culture.

The first dimension is regarding public culture governance as an ideological leading tool with strong political overtones. With the rising of democratic consciousness in modern society, the political attribute of public culture has not been gradually eliminated. On the contrary, it has been reinterpreted as "the ideological view of describing meaning" [9] in the social science field and used to guide and regulate the cultural ideas and ideologies of the public through the nationally recognized values.

The second dimension pays attention to the crucial influence of cultural industry production on social development, and expects to regulate the production attribute of cultural industry through public culture governance. In the wave of economic globalization, culture has become an independent economic system. As one of the engines of economic development, the culture industry has been thriving. The public ideology transformation through public culture in residents' daily life cannot be separated from the healthy development of the cultural industry. So, started from the value concern of Humanism and the praise and longing for the cultural production in the whole society, more and more scholars began making a detailed inquiry of social value dimension of cultural production, appealed the regression of political attribute of cultural production by the means of public culture governance [10-13].

The third dimension appeal the culture return to ordinary people gossip, concerned about the cultural life governance of the masses' daily life, aims to tap the various latent meanings contained in public culture life. "The final result of history arises from the conflict of many single wills. Countless desires have been intertwined with each other, and their complex efforts have spawned something that no one has ever hoped for." [14] The public culture exists in the ordinary life of ordinary people, belongs to the concept of structure and value meaning of a country, a place or a community. Based on this cognition, some scholars tend to carry out the study of public culture governance through specific case studies. Through deep into the actual administrative process of government, the daily life of ordinary people and the actual service activities of cultural organizations, they get the research materials and inspiration. [15]

\section{Three Functions of Public Culture Governance}

Starting from the three connotations of public culture governance, research paper can draw out its three functions.

First of all, public culture, as an important carrier of ideological guidance, has a social governance role at the political level. Political governance is the inherent attribute of culture. In the period of social transformation and the modernization of governance, the governance of public culture is becoming more and more prominent. It is regarded as one of the methods of effective governance of modern social life, and it plays a fundamental role in political governance. Since the 18th National Congress of the Communist Party of China, the whole society has reached a common view: In the process of urban cultural construction, the core values of Chinese socialism should be integrated into the spiritual quality of citizens through public culture governance action. With the public cultural space, the country will gradually change from a political community into a social consciousness community. 
Secondly, the public culture is an important tool for managing the way of life, it has the ultimate meaning for the lives of residents. Public culture is a kind of cultural governance that is committed to improving the social culture life of the masses and bridging the differentiation of social stratum [16]. In recent years, the study of public culture governance has increasingly turned to the function of life. Researchers pay more and more attention to the subjective cognition of micro action subject of social culture life, which highlights the important status of life attribute of public culture governance. It is a comprehensive governance aimed at attracting broad participation of the masses and surrounding the cultural life of the public.

Thirdly, public culture governance regards call back the public value of cultural products as its natural mission at the culture supply level. Culture has been the material carrier of cultural infiltration since ancient times, which makes the cultural industry inherently have the function of social control. In the new period, the public spirit of public culture governance action is committed to maintaining the supply of cultural field, will be made public cultural identity as the fundamental criterion of cultural production, so as to prevent cultural development deviating from the original idea of the state reform.

\section{The Focus of Public Culture Governance Research -- The Value Concern of Culture Governance}

First of all, the study of public culture governance needs to examine the practice of a full range of public culture service systems, which are carried out by the government in order to achieve the political objectives of the government, such as government administration, residents' lives and cultural provision. The governance of public culture has multiple functions. Public culture service is the concrete bearer of the governance of public culture, playing the role of an implementer of public culture governance in daily life. Therefore, the research in this field requires deep description for the government in the cultural governance under the guidance of thinking for multiple functions of public culture services in many aspects of the practice process of system development and implementation, in order to obtain government action logic and driving factors.

Secondly, the study of public culture governance needs to examine the micro strategy and inner world of the public culture service practice that residents participate in in daily life. The life attribute of public culture governance endows culture with neutral color. This has enabled the field to study the cultural implications of cultural patterns, lifestyles, and the ways in which they behave. It emphasizes the initiative and creativity of the public, and believes that culture is closely related to everyday life and sees culture as a way of life. In this sense, understanding of culture, then residents' daily life will have a decisive cultural significance. Researchers "should understand the mechanisms by which diverse texts become part of a production style or type system...... makes modern culture research not only a kind of academic enthusiasm, but also become a part of striving for a better society and life" [17]. At this level, to understand the public culture service in cultural governance should be regarded as a kind of service in cultural life. The services it provides must first be embedded in the daily cultural environment of residents, and become part of the cultural life of the residents. This means that in the field of public culture governance, public culture service should be oriented to the cultural life of the public, around the real demands of the residents to promote the construction and truly regard residents as the masters of public culture services. Thus, it will has the ability to attract the majority of residents to participate fully and to find self-value satisfaction. Following this thought, the research needs of community residents into the daily public cultural life, into their tangled heart, struggle and persistence, understanding their true emotional world, and then dig a vivid individual, colorful, interesting psychological motivation and value ideal.

Thirdly, the study of public culture governance needs to examine the survival strategy and development logic that cultural service organizations and cultural enterprises provide public culture services in the situation of cultural governance. The key problem that the government needs to solve in carrying out effective public culture service is based on the cognition of the function of the public culture governance at the cultural supply level, and use the cultural organizations to fully mobilize all kinds of social resources so as to promote the healthy development of social culture. In this procedure, the government and cultural organization should be the equal subjects of the reasonable and scientific public culture service system, and each has its own function, positioning and cooperation with each other to provide healthy and popular cultural products and services to residents. At the same time, in the practice of community public culture service, the government should also encourage cultural enterprises to participate in the construction of cultural service system, through the community residents to provide public cultural products to establish a corporate reputation, to propagate a corporate public image. It makes the function of the cultural service systematized and integrated, and forms a mature operation mechanism. This needs to go deep into the real operation process of the cultural service organizations and enterprises, and study carefully how they survive and develop in the actual opportunities and objective constraints.

Fourthly, the study of public culture governance needs to explore the interactive mechanism of multiple participants in the cultural governance field. The three functions of public culture service in cultural governance are closely linked and inseparable, and they define the public culture service field as an interactive field which is participated by many subjects, such as the government, residents, cultural organizations and so on [18]. In this field of different cultural structures and social institutions, multiple subject action take different action strategies public culture service practice because of its power and different resources can be used in, and then form a different nature of interaction between each other. Therefore, 
to understand the current public culture service practice full view, the system practice must set out from the multiple functions in the country, the life and the culture of supply of culture governance, to understand the interaction between the ideal and reality of the state government, residents, organizations in the system of the three. Accordingly, it is necessary to study the interaction between the three parties in the practice of public culture service (as shown in Figure 1).

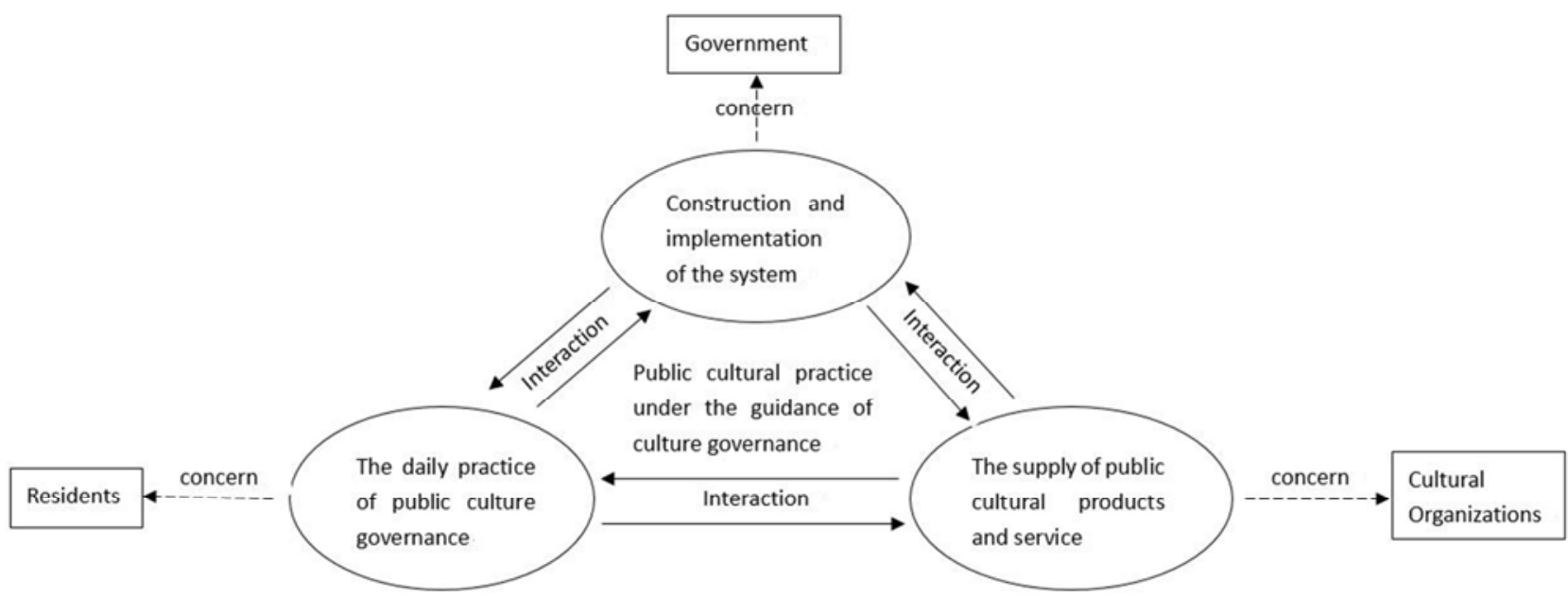

Figure 1. The practical field and interactive relation of the tri-subject.

\section{Conclusion}

In short, under the changing background of culture ideas and cognition, the governance of public culture has developed economic attributes from political ideology, and then it is independent as a key element that can construct the whole social life. The intertwined winding and theoretical accumulation between the three attributes actually deduces its constructive function in the social operation of politics, life and culture supply. The intertwined and transformed of this kind of public culture and its governance attribute in the political, life and supply side of the three functions, constitutes an important theoretical horizon for the construction of public culture service system in the period of modern transformation. It is also the starting point and standpoint of understanding the practice of public culture service.

At the same time, the researchers also need to note that modern society is not only a democratic society, but also a manifestation of diverse and individualized life of society, as Max Weber said: Our time is a rational time, especially a time to dispel the mystery of the world; the fate of our time or the ultimate and noblest of all values is a universal love. It has disappeared in the life, or be into the mystery of life, or be a direct relationship between the individuals [19]. In the socialist China, which constantly adjusts the governance concept of public culture, along with the lack of public values of cultural industries in the process of economic transformation, the realization of civil rights through the basic platform of public culture service has become a key step in the cultural construction of government. Up to this day, the construction of public culture service is interpreted by the original value concern of the government as a concrete practice of keeping pace with the real life. With the introduction of relevant service standards and policies, the cultural connotation of public culture services has gradually expanded from the protection of the basic cultural rights of vulnerable groups to the national ideal of reshaping the public spirit by meeting the diverse cultural needs of modern people.

\section{Acknowledgements}

Project supported by a grant from the Projects of the National Social Science Foundation of China: "Innovative mechanism of synergy governance and residents' initiative participation mechanism of metropolitan community culture" (Grant No. $17 \mathrm{CSH}$ 008) and the Fundamental Research Funds for the Central Universities: "The innovation research of public culture service in Jiangsu urban community" (Grant No. 2016 B 14414).

\section{References}

[1] With China's high degree of economic growth, social differentiation is becoming increasingly serious. There has been a strong "big government" position, making the government to provide public services as the people's ideological habits. The overwhelming government's social responsibility and the apathy of people's self-service awareness lead to the formation of the plight of the government. The structural tension caused by the lack of endogenous mechanisms of social order and the rapid rise of people's sense of insecurity result in the number and size of mass incidents are increasing year by year.

[2] Wu Yue. The deviation and internal logic of government purchase of public service [J]. Truth Seeking, 2015 (10).

[3] Zhang Huan \& Chu Yongqiang. Are Community Services "the Catalysts" of Community Development?_Evidence from 108 Communities in Urban China [J]. Journal of Sichuan University (Social Science Edition), 2015 (6). 
[4] Chen Yuetang \& Xiong Liang. The dilemma and Countermeasures of Non-profit organization participating in the provision of public goods in the community. Social Science In Hunan, 2015 (5).

[5] Michael Mann. The Sources of Social Power [M]. Liu Beicheng, etc. Trans. Shanghai: Shanghai Renmin Chubanshe, 2002: page 10 .

[6] Charles Taylor. The Malaise of Modernity [M]. Cheng Lian Trans. Beijing: Central Compilation \& Translation Bureau, 2001: page 4 .

[7] Zhou Yi. Strong and Weak Cultural Programs: Reading J. C. Alexander's Cultural Hermeneutics [J]. Sociological Studies, 2008 (6): 33-53.

[8] Hannah Arendt. The Origins of Totalitarianism [M]. Lin Xianghua Trans. Beijing: SDX Joint Publishing Company, 2008: page 147.

[9] Xu Lianming, Wen Jun. On the perspective of sociology of ideology [J]. Jianghai Academic Journal, 2007 (2): 32-37.

[10] Tao Dongfeng. Reconstruct the political dimension of literary theory [J]. Literary Contention, 2008 (1): 23-27.

[11] Meng Dengying. Political consciousness and identity reflection of cultural studies - Also on how to treat the dilemma of cultural studies in China [J]. Marxism \& Reality, 2012 (6): 82-86.
[12] Sun Shicong. Cultural industry and cultural surplus value from the reflection of Adorno's theory of cultural industry [J]. Dongyue Tribune, 2013 (2): 56-62.

[13] Tan Yang. The influence of cultural factors in the process of modernization - Concurrently on the transformation of politics to culture [J]. Chinese Culture Research, 2014 (2): 74-80.

[14] Engels Engels to Joshua Bloch (21-22 September 1890) [M]. "Selected Works of Marx and Engels", Volume 4, Beijing: People's Publishing House, 1972: p. 249.

[15] Marxism and Reality, 2012 (6): 112-118 [J]. Marxism and Reality, 2012 (6): 112-118. [J]. Marxism and Reality, 2012 (6): 112-118.

[16] Li Lulu \& Zhong Zhifeng. "Divided Post-Authoritarianism": An Analysis of the Political Value and Its Evolution in China's. Transitional Society. Open Times, 2015 (1).

[17] Douglas Kielner. Cultural Marxism and Modern Culture Research [J]. The Journal of Shanghai Administration Institute, 2006 (9): 42-50.

[18] The construction of cultivation mechanism and the system support of the tri-integration ability of society organizations. Study and Practice, 2015 (6).

[19] Max Weber. Weber works (1): Academic and Political [M]. Qian Yongxiang, etc. Trans. Guilin: Guangxi Normal University Press, 2004: p. 190. 